\title{
Is pyrite an important sink for Mo? Evidence from XAFS, TEM and APT analyses of pyrite
}

\author{
DANIEL GREGORY ${ }^{1}$ ANTHONY CHAPPAZ ${ }^{2}$ NICOLE \\ ATIENZA ${ }^{1}$ SANDRA TAYLOR ${ }^{3}$ DANIEL E. PEREA ${ }^{3}$ LIBOR \\ KOVARIK $^{3}$ AND TIMOTHY LYONS ${ }^{4}$ \\ ${ }^{1}$ Department of Earth Sciences, University of Toronto, \\ daniel.gregory@utoronto.ca \\ ${ }^{2}$ STARLAB, Dept. of Earth and Atmospheric Sciences, \\ Central Michigan University, USA \\ ${ }^{3}$ Environmental molecular Sciences Laboratory, Pacific \\ Northwest National Laboratory, Richland, WA, USA \\ ${ }^{4}$ University of California, Riverside
}

Molybdenum (Mo) is a well established paleo-redox proxy. Originally, under anoxic/euxinic conditions, Mo was thought to be predominantly held within the pyrite crystal lattice. However, recent studies have cast some doubt on that presumtion, suggesting that large amounts of Mo are also held within organic matter or other pahses. However, LAICPMS analyses in these studies still suggest high amounts of Mo in pyrite, interpretted by inspection of time resolved laser ablation to be as substitutions into the pyrite structure (Gregory, et al. 2015).

In the present study, we used a comination of bulk and atomic to near-atomic analyses to better undertstand the distribution of Mo in individual pyrite framboids in sediment samples from the Cariaco Basin. Bulk-scale analysis using XAFS suggests that Mo is present as Mo(VI) in an oxygenbound octahedral configuration. Further, a second was identified. This phase is not pyrite but rather resembles a Mo$\mathrm{Fe}-\mathrm{S}$ phase recently synthetized, suggesting that Mo is not held within pyrite. Atomic to near-atomic scale analyses using TEM and APT reveal an absence of Mo atoms in pyrite framboids - a surprising result considering $\sim 1000 \mathrm{ppm} \mathrm{Mo}$ concentratoins measured by LA-ICPMS. This result suggests that Mo must be concentrated within the same microenviroments that pyrite forms in but is not directly associated with pyrite itself. Thus Mo geochemistry in reducing systems seems to be more complicated than currently understood, and perhaps the community should consider such complexities when using it as a paleo-redox proxy.

Gregory, D. D., et. al. (2015). "Trace Element Content of Sedimentary Pyrite in Black Shales." Economic Geology 110(6): 1389-1410. 